Check for updates

Cite this: Chem. Sci., 2018, 9, 6839

¿ All publication charges for this article have been paid for by the Royal Society of Chemistry

Received 11th May 2018

Accepted 17th July 2018

DOI: $10.1039 / \mathrm{c} 8 \mathrm{sc} 02101 \mathrm{e}$

rsc.li/chemical-science

\section{Nickel(0)-catalyzed linear-selective hydroarylation of unactivated alkenes and styrenes with aryl boronic acids $\uparrow$}

\author{
Honggui Lv, Li-Jun Xiao, Dongbing Zhao (iD * and Qi-Lin Zhou (iD
}

Herein, we describe the first linear-selective hydroarylation reaction of unactivated alkenes and styrenes with aryl boronic acids, which was achieved by introducing a directing group on the alkenes. This efficient, scalable reaction serves as a method for modular assembly of structurally diverse alkyl arenes, including $\gamma$-aryl butyric acid derivatives, which are widely utilized as chemical building blocks for the synthesis of various drugs and other biologically active compounds.

\section{Introduction}

Transition-metal-catalyzed alkene hydroarylation involving metal hydrides $(\mathrm{M}-\mathrm{H})^{1}$ has become one of the most widely used strategies for the synthesis of alkyl arenes. ${ }^{2}$ To date, three types of aryl sources have been used for this purpose: (1) simple arenes, (2) aryl halides, and (3) aryl metals (i.e., aryl stannanes or boronic acids). The simple arenes are usually restricted to heteroarenes and arenes with a directing group because of the challenge of activating the inert $\mathrm{C}-\mathrm{H}$ bonds of simple arenes. ${ }^{3}$ Aryl halides and aryl metals as the aryl sources require the use of $\mathrm{O}_{2}$ or an excess of a reductant (such as a silane or an alkyl halide), which limits the practicality of alkene hydroarylations with these two sources (Scheme 1a)., ${ }^{4,5}$ A significant breakthrough was made by Zhou et al., who reported a highly selective Ni-catalyzed hydroarylation of styrenes and 1,3-dienes with aryl boron compounds under redox-neutral conditions (Scheme 1b). ${ }^{6}$ However, this method still suffers from some limitations: (1) the reaction is efficient only with styrene and 1,3-diene substrates, and (2) only branched products can be achieved.

Inspired by recent work on olefin functionalization reactions in which the reactivity and regioselectivity are controlled via the introduction of a coordinating group, ${ }^{7,8}$ we have developed the first method for directing-group-controlled linear-selective hydroarylation of unactivated alkenes and styrenes with aryl boronic acids under redox-neutral conditions (Scheme 1c). This efficient, scalable reaction serves as a method for modular assembly of structurally diverse alkyl arenes, including $\gamma$-aryl butyric acid derivatives, which are widely utilized as chemical

State Key Laboratory and Institute of Elemento-Organic Chemistry, College of Chemistry, Nankai University, 94 Weijin Road, Tianjin 300071, China. E-mail: dongbing.chem@nankai.edu.cn

$\dagger$ Electronic supplementary information (ESI) available. CCDC 1838875. For ESI and crystallographic data in CIF or other electronic format see DOI: $10.1039 / \mathrm{c} 8 \mathrm{sc} 02101 \mathrm{e}$ building blocks for the synthesis of various drugs and other biologically active compounds (Scheme 1 ). $\gamma$-Aryl butyric acids are traditionally prepared by Friedel-Crafts reactions between arenes and butyrolactones, ${ }^{9}$ but this method suffers from disadvantages such as harsh reaction conditions, limited substrate scope (it is suitable only for electron-rich arenes), and poor regioselectivity.

\section{Results and discussion}

In a preliminary experiment, we found that treatment of 3butenoic acid derivative 1a $(0.2 \mathrm{mmol})$, which bears an 8 -

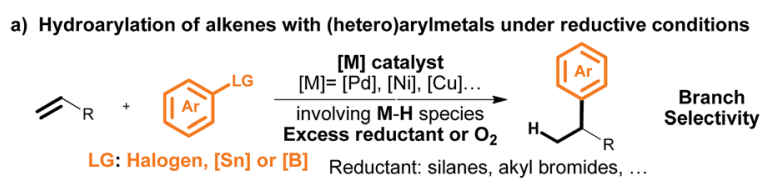

b) Hydroarylation of alkenes with (hetero)arylmetals under redox neutral conditions

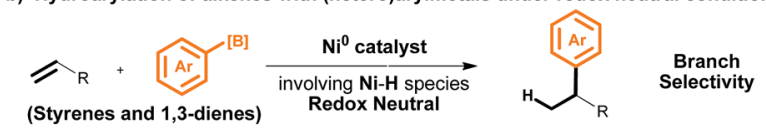

c) This work
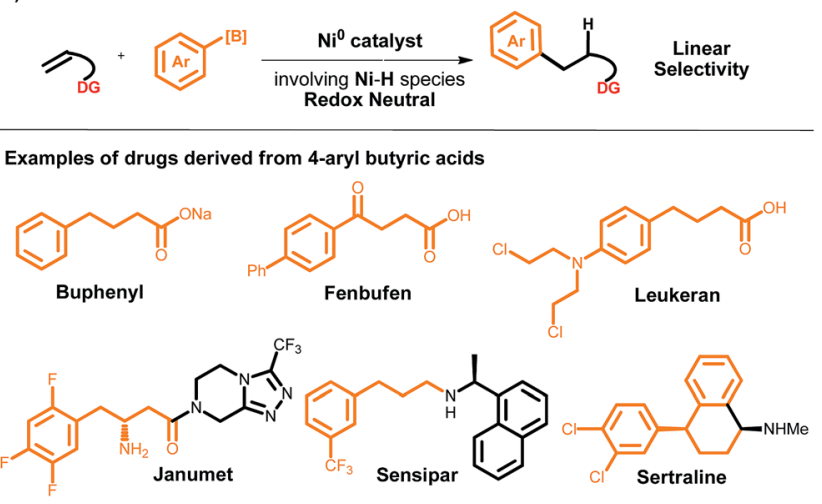

Scheme 1 Transition-metal-catalyzed hydroarylation of alkenes involving $\mathrm{M}-\mathrm{H}$ and examples of drugs derived from 4-aryl butyric acids. 
aminoquinoline (AQ) directing group, with $\mathrm{Ni}(\mathrm{COD})_{2}(5 \mathrm{~mol} \%)$, $\mathrm{PCy}_{3}(10 \mathrm{~mol} \%)$, and 2-naphthalenylboronic acid 2a $(0.3 \mathrm{mmol})$ in $\mathrm{MeOH}(1 \mathrm{~mL})$ at $70{ }^{\circ} \mathrm{C}$ for $24 \mathrm{~h}$ gave linear product 3a in $21 \%$ yield (Table 1 , entry 1 ). Replacing $\mathrm{MeOH}$ with $t$-amyl alcohol slightly improved the yield (entry 2), and adding 1.5 equiv. of $\mathrm{K}_{2} \mathrm{CO}_{3}$ improved the yield even further (to $38 \%$, entry 3). Evaluation of different bases revealed that CsOPiv was the best choice (entries 3-7). We also found that changing the 1a/2a molar ratio to $1: 2$ increased the yield to $61 \%$ (entry 8 ). Finally, various phosphine ligands were investigated (entries 9-12); switching from $\mathrm{PCy}_{3}$ to $\mathrm{PPh}_{3}$ dramatically improved the yield (to $85 \%$, entry 9). A control experiment confirmed that the reaction did not occur in the absence of $\mathrm{Ni}(\mathrm{COD})_{2}$ (entry 13).

Next, we investigated the substrate scope with respect to the aryl boronic acid by carrying out reactions with 3-butenoic acid derivative 1a as the alkene (Scheme 2). To our delight, electronrich, electron-poor, and sterically hindered aryl boronic acids all afforded the desired products in good to excellent yields (3a$3 \mathbf{u}$ ). Heteroaryl boronic acids were also reactive ( $3 \mathbf{v}$ and $3 \mathbf{w}$ ), as was an alkenyl boronic acid, which selectively afforded (E)-6phenylhexenoic acid derivative $\mathbf{3 x}$ under the optimized conditions. In addition, we found that a high yield of $\mathbf{3} \mathbf{b}$ could be obtained by hydroarylation of 1a with an aryl boroxine or an aryl boronic ester as the aryl source. It is important to stress that these reaction conditions were compatible with a remarkable variety of functional groups on the aryl boronic acids, including halogens (F, Cl, and $\mathrm{Br}$ ) and acetyl, cyano, and methoxy groups, yielding products (3i-3s) that could be subjected to further

Table 1 Optimization of directed hydroarylation of unactivated alkene 1 a with 2-naphthalenylboronic acid $2 a^{a}$

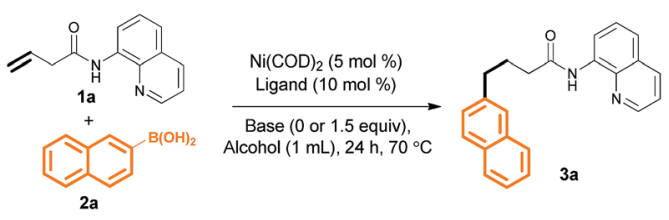

\begin{tabular}{lllll}
\hline Entry & Ligand & Base & Solvent (H source) & Yield $^{b}[\%]$ \\
\hline 1 & $\mathrm{PCy}_{3}$ & - & MeOH & 21 \\
2 & $\mathrm{PCy}_{3}$ & - & $t$-AmylOH & 29 \\
3 & $\mathrm{PCy}_{3}$ & $\mathrm{~K}_{2} \mathrm{CO}_{3}$ & $t$-AmylOH & 38 \\
4 & $\mathrm{PCy}_{3}$ & $\mathrm{KHCO}_{3}$ & $t$-AmylOH & 23 \\
5 & $\mathrm{PCy}_{3}$ & $\mathrm{~K}_{3} \mathrm{PO}_{4}$ & $t$-AmylOH & 43 \\
6 & $\mathrm{PCy}_{3}$ & $\mathrm{NaO} t \mathrm{Bu}$ & $t$-AmylOH & $\mathrm{NR}$ \\
7 & $\mathrm{PCy}_{3}$ & CsOPiv & $t$-AmylOH & 53 \\
$8^{c}$ & $\mathrm{PCy}_{3}$ & CsOPiv & $t$-AmylOH & 61 \\
$9^{c}$ & $\mathbf{P P h}_{3}$ & CsOPiv & $t$-AmylOH & $\mathbf{8 6}(\mathbf{8 5})^{d}$ \\
$10^{c}$ & $\mathrm{CyPPh}_{2}$ & CsOPiv & $t$-AmylOH & 77 \\
$11^{c}$ & $\mathrm{~S}^{c} \mathrm{Phos}^{c}$ & CsOPiv & $t$-AmylOH & 33 \\
$12^{c}$ & $\mathrm{XantPhos}$ & CsOPiv & $t$-AmylOH & 59 \\
$13^{e}$ & $\mathrm{PPh}_{3}$ & CsOPiv & $t$-AmylOH & $\mathrm{NR}$
\end{tabular}

${ }^{a}$ Reactions were carried out with $\mathrm{Ni}(\mathrm{COD})_{2}$ (5 mol\%), ligand (10 mol\%), base ( 0 or 1.5 equiv.), $1 \mathrm{a}(0.2 \mathrm{mmol})$, and 2-naphthalenylboronic acid (2a, $0.3 \mathrm{mmol})$ in solvent $(1 \mathrm{~mL})$ for $48 \mathrm{~h}$ at $25{ }^{\circ} \mathrm{C}$ under a $\mathrm{N}_{2}$ atmosphere. ${ }^{b}$ Yields were determined by NMR spectroscopy with an internal standard. $\mathrm{NR}=$ no reaction. ${ }^{c} 2.0$ equiv. of $2 \mathrm{a}$ was used. ${ }^{d}$ The isolated yield is given in parenthesis. ${ }^{e}$ Reaction without $\mathrm{Ni}(\mathrm{COD})_{2}$.

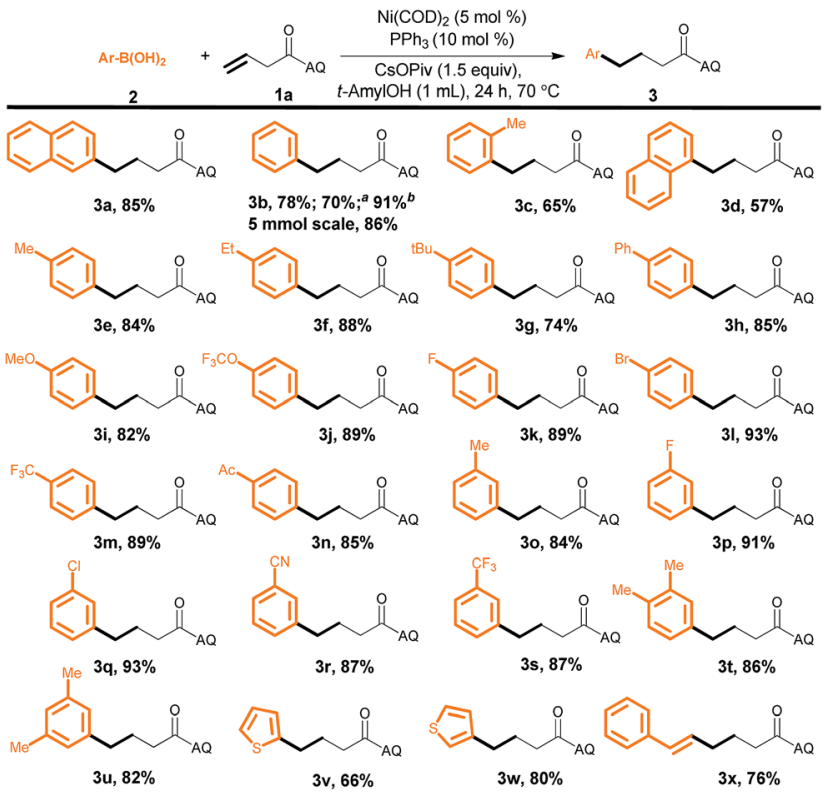

Scheme 2 The reactions of diverse aryl boronic acids 2 with 3butenoic acid derivative 1a. Yield of isolated product is given. ${ }^{a} 5,5-$ Dimethyl-2-phenyl-1,3,2-dioxaborinane was used as the aryl source. ${ }^{b}$ Triphenylboroxine was used as the aryl source.

synthetic transformations. In addition, the reaction could be carried out on gram scale without a decrease in the yield $(1.5 \mathrm{~g}$ of $\mathbf{3 b}, 86 \%)$. The structure of $\mathbf{3 b}$ was confirmed by X-ray diffraction analysis of a single crystal. ${ }^{10}$

We next evaluated the utility of this method for various unactivated alkenes (Scheme 3). Terminal alkenes bearing a single substituent at the $\alpha$ - or $\beta$-position reacted smoothly to afford the desired products in good to excellent yields (4a and 4b). A sterically congested $\alpha, \alpha$-disubstituted terminal alkene was also reactive, furnishing desired product $\mathbf{4 c}$ in moderate yield, although a higher temperature $\left(125{ }^{\circ} \mathrm{C}\right)$ and a higher loading(10 mol\%) of a different ligand, $\mathrm{PhPMe}_{2}$, were required. Furthermore, internal alkenes bearing a variety of substituents at the $\gamma$-position could also be efficiently converted into the

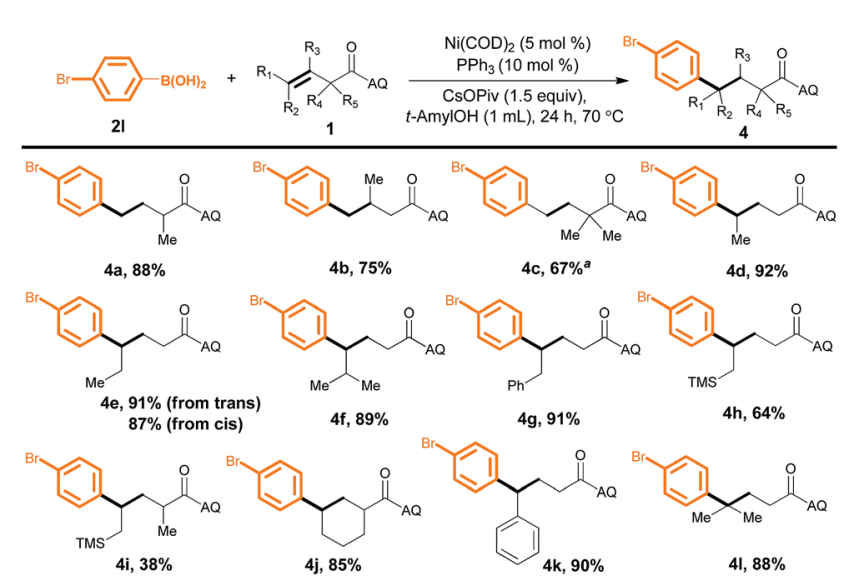

Scheme 3 Reactions of unactivated alkenes with aryl boronic acid $2 \mathrm{l}$. Yield of isolated product is given. ${ }^{a} \mathrm{PhPMe}_{2}(10 \mathrm{~mol} \%)$ as the ligand at $125^{\circ} \mathrm{C}$. 
corresponding products (4d-4l); the steric and electronic effects of the substituents appeared to be negligible. Notably, the yields of $4 \mathbf{e}$ from trans- and cis-3-hexenoic acid were essentially the same. In addition, $\alpha, \gamma$-disubstituted alkenes gave desired products $\mathbf{4 i}$ and $\mathbf{4 j}$. Surprisingly, a $\gamma, \gamma$-disubstituted alkene could also be hydroarylated to produce compound $4 \mathbf{1}$ (88\%), which has a quaternary carbon center.

We wondered whether the introduction of the AQ directing group at the ortho-position of styrene would result in linear selectivity rather than the branched selectivity reported by Sigman et al. and Zhou et al. for hydroarylation of styrenes with aryl metals. ${ }^{4,6}$ After extensive investigation, we found, to our delight, that reactions of styrene derivative $\mathbf{1 m}$ with various aryl boronic acids occurred smoothly with completely linear selectivity and in moderate yield by employment of $\mathrm{PhPCy}_{2}$ as the ligand and higher catalyst loading (10 mol\% $\left.\mathrm{Ni}(\mathrm{COD})_{2}\right)$, higher temperature $\left(125{ }^{\circ} \mathrm{C}\right)$, and longer reaction time (Scheme 4$)$. This result clearly proved that the directing group controlled the regioselectivity of the hydrometalation.

The products obtained by the method described herein could provide access to structurally diverse synthetic building blocks by means of additional transformations (Scheme 5, upper panel). Specifically, removal of the AQ directing group of 3b smoothly provided 4-phenylbutanoic acid (5b) in 97\% yield. Acid 5b could undergo intramolecular cyclization to yield tetralin-derivative $\mathbf{6 a}$, or the carboxyl group could be replaced with an iodine atom (6b). Five-membered lactone $\mathbf{6 c}$ could be obtained by treatment of $\mathbf{5 b}$ with a hypervalent iodine reagent,

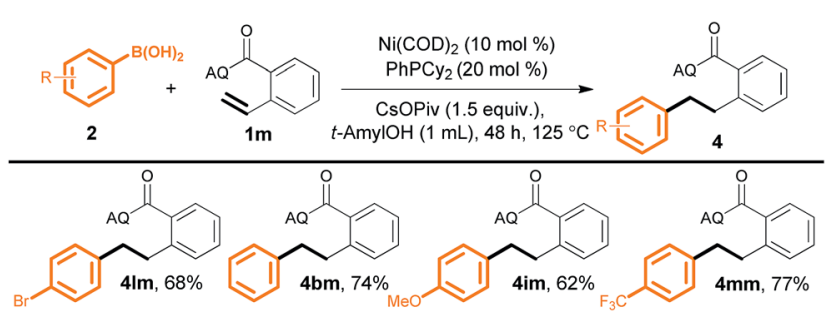

Scheme 4 Reactions of styrene derivative $1 \mathrm{~m}$ with aryl boronic acids.

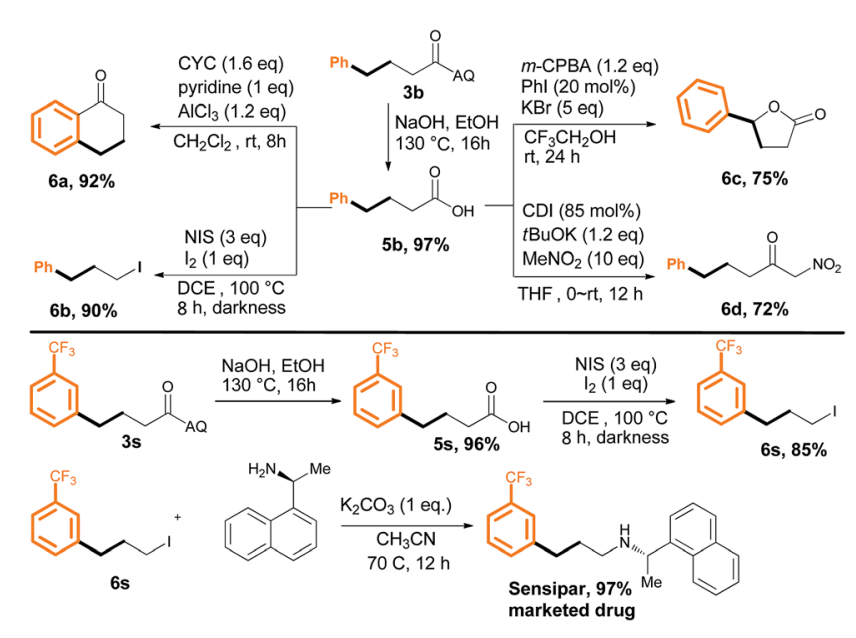

Scheme 5 Transformations of hydroarylation products $3 \mathrm{~b}$ and $3 \mathrm{~s}$. and $\mathbf{5 b}$ readily underwent attack by $\mathrm{CH}_{3} \mathrm{NO}_{2}$ to afford corresponding ketone derivative 6d. To further demonstrate the synthetic usefulness of our method, we synthesized the drug Sensipar from 3s (Scheme 5, lower panel). First, free acid 5s was synthesized by removal of the AQ directing group, and then the acid was transformed into the corresponding alkyl iodide (6s) by treatment with $\mathrm{NIS} / \mathrm{I}_{2}$ in DCE. Simple amination of $6 \mathbf{s}$ gave Sensipar in $97 \%$ yield.

To probe the reaction mechanism, we carried out a control experiment and a series of deuteration experiments (Scheme 6). We found that no reaction occurred when $N$-(naphthalenyl) butenamide 7 and 2-naphthalenylboronic acid (1a) were used as the substrates (eqn (1)). This result indicates that the presence of the AQ directing group on the unactivated alkene was indispensable. Treatment of $\mathrm{PhB}(\mathrm{OD})_{2}$ 2b-D with alkene $\mathbf{1 a}$ in $\mathrm{MeOH}$ or treatment of $(\mathrm{PhBO})_{3}$ with $1 \mathrm{a}$ in $\mathrm{CD}_{3} \mathrm{OH}$ gave undeuterated product $\mathbf{3 b}$ (eqn (2) and (3)). However, the use of MeOD as the solvent led to the formation of $\mathbf{3} \mathbf{b}$ that was only partially deuterated at both the $\alpha$ - and $\beta$-positions (eqn (4)), which reveals that the hydrogen atom of the $\mathrm{Ni}-\mathrm{H}$ intermediate $\mathbf{A}$ (Scheme 7) came from the methanol $\mathrm{O}-\mathrm{H}$ group and

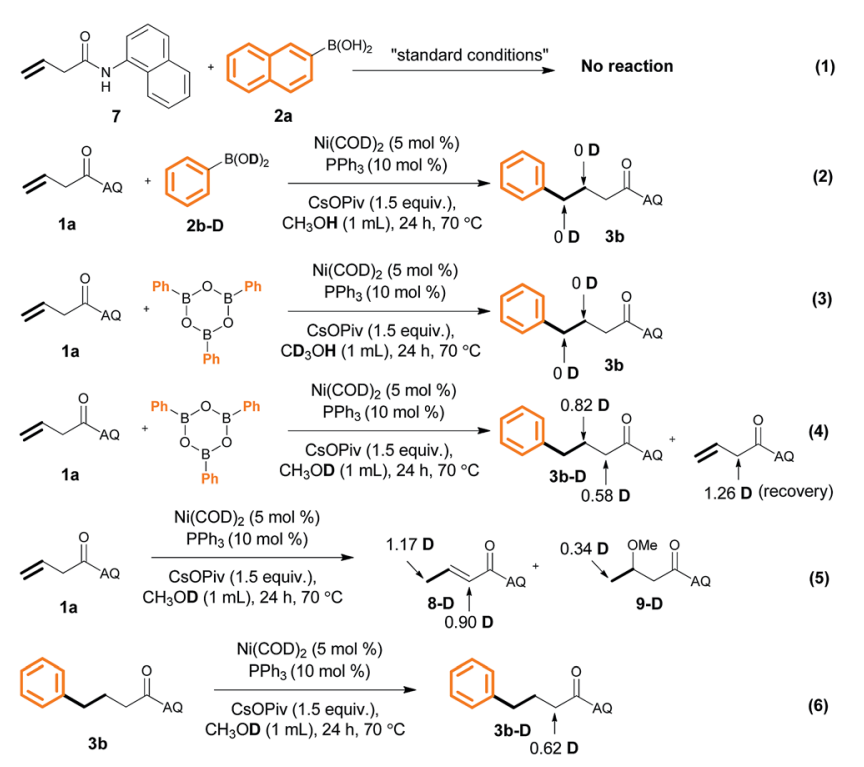

Scheme 6 Control experiment and deuteration experiments.

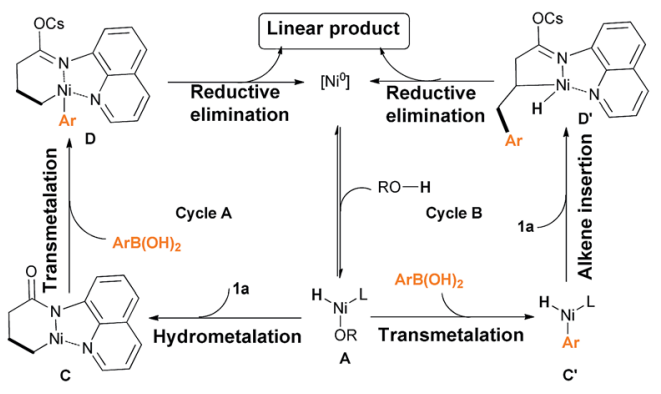

Scheme 7 Proposed mechanism of the Ni(0)-catalyzed directinggroup-controlled hydroarylation of unactivated alkenes with aryl boronic acids. 
hydrometalation of $\mathrm{Ni}-\mathrm{H}$ is irreversible in the presence of aryl boronic acid. Further experiment suggests that hydrometalation of starting material 1a via $\mathrm{Ni}-\mathrm{H}$ species would also happen to form 5-membered nickelacycle and is reversible in the absence of aryl boronic acid under our reaction conditions (eqn (5) and (6)). Additionally, the deuteration of $\alpha$-positions might be because of CsOPiv base.

On the basis of literature reports and our own mechanistic experiments, we propose two catalytic cycles that starts with the reversible formation of $\mathrm{Ni}-\mathrm{H}$ species $\mathbf{A}$ (Scheme 7). For path A, coordination and subsequent hydrometalation of the $\mathrm{C}=\mathrm{C}$ bond affords the six-membered nickelacyclic intermediate $\mathbf{C}$, and then transmetalation of the aryl boronic acid generates intermediate $\mathbf{D}^{\mathbf{1 1}}$ Finally, reductive elimination gives the desired product and regenerates the $\mathrm{Ni}(0)$ catalyst. Alternatively, intermediate A could also undergo transmetalation first to form Aryl-Ni-H species $\mathrm{C}^{\prime}$, and then alkene insertion to form fivemembered nickelacyclic intermediate $\mathbf{D}^{\prime}$, which would involve reductive elimination to yield the same linear product. Note, that we have detected the production of naphthalene under our reaction condition. It indicated that cycle $\mathrm{B}$ might be the real process. However, at this stage, we still can't rule out cycle A.

\section{Conclusions}

In conclusion, we have described the first method for $\mathrm{Ni}(0)$ catalyzed directing-group-controlled linear-selective hydroarylation of unactivated alkenes and styrenes with aryl boronic acids under redox-neutral conditions. Our efficient, scalable method provides a general route to structurally diverse alkyl arene derivatives, including $\gamma$-aryl butyric acid derivatives, which are widely utilized as chemical feedstocks for the preparation of drugs and other biologically active compounds.

\section{Conflicts of interest}

There are no conflicts to declare.

\section{Acknowledgements}

We are grateful for the financial support from the National Natural Science Foundation of China (21602115), 1000-Talent Youth Program (020/BF180181), the Natural Science Foundation of Tianjin (18JCYBJC20400), the Fundamental Research Funds for the Central Universities and Nankai University.

\section{Notes and references}

1 For some reviews on metal-hydride chemistry, see: (a) S. Rendler and M. Oestreich, Angew. Chem., Int. Ed., 2007, 46, 498; (b) C. Deutsch, N. Krause and B. H. Lipshutz, Chem. Rev., 2008, 108, 2916; (c) M. T. Pirnot, Y.-M. Wang and S. L. Buchwald, Angew. Chem., Int. Ed., 2016, 55, 48; (d) M. D. Greenhalgh, A. S. Jones and S. P. Thomas, ChemCatChem, 2015, 7, 190; (e) R. M. Maksymowicz, A. J. Bissette and S. P. Fletcher, Chem.-Eur. J., 2015, 21,
5668; (f) S. W. M. Crossley, C. Obradors, R. M. Martinez and R. A. Shenvi, Chem. Rev., 2016, 116, 8912; $(g)$ K. D. Nguyen, B. Y. Park, T. Luong, H. Sato, V. J. Garza and M. J. Krische, Science, 2016, 354, 300.

2 For some reviews on hydroarylation of alkenes, see: $(a)$ F. Kakiuchi and S. Murai, Acc. Chem. Res., 2002, 35, 826; (b) S. Pan and T. Shibata, ACS Catal., 2013, 3, 704; (c) X. Zeng, Chem. Rev., 2013, 113, 6864; (d) L. Yang and H. Huang, Chem. Rev., 2015, 115, 3468; (e) G. E. M. Crisenza and J. F. Bower, Chem. Lett., 2016, 45, 2; $f$ ) Z. Dong, Z. Ren, S. J. Thompson, Y. Xu and G. Dong, Chem. Rev., 2017, 117, 9333.

3 For some examples on hydroarylation of alkenes using arenes as the aryl source, see: (a) Z.-M. Sun, J. Zhang, R. S. Manan and P. Zhao, J. Am. Chem. Soc., 2010, 132, 6935; (b) Y. Nakao, Y. Yamada, N. Kashihara and T. Hiyama, J. Am. Chem. Soc., 2010, 132, 13666; (c) K. Gao and N. Yoshikai, J. Am. Chem. Soc., 2011, 133, 400; (d) B.-T. Guan and Z. Hou, J. Am. Chem. Soc., 2011, 133, 18086; (e) J. Oyamada and Z. Hou, Angew. Chem., Int. Ed., 2012, 51, 12828; (f) S. Pan, N. Ryu and T. Shibata, J. Am. Chem. Soc., 2012, 134, 17474; (g) P.-S. Lee and N. Yoshikai, Angew. Chem., Int. Ed., 2013, 52, 1240; (h) T. Andou, Y. Saga, H. Komai, S. Matsunaga and M. Kanai, Angew. Chem., Int. Ed., 2013, 52, 3213; (i) W. Xu and N. Yoshikai, Angew. Chem., Int. Ed., 2014, 53, 14166; (j) G. E. M. Crisenza, N. G. McCreanor and J. F. Bower, J. Am. Chem. Soc., 2014, 136, 10258; $(k)$ J. S. Bair, Y. Schramm, A. G. Sergeev, E. Clot, O. Eisenstein and J. F. Hartwig, J. Am. Chem. Soc., 2014, 136, 13098; ( $l$ ) G. E. M. Crisenza, O. O. Sokolova and J. F. Bower, Angew. Chem., Int. Ed., 2015, 54, 14866; (m) Y. Schramm, M. Takeuchi, K. Semba, Y. Nakao and J. F. Hartwig, J. Am. Chem. Soc., 2015, 137, 12215; (n) Y. Ebe and T. Nishimura, J. Am. Chem. Soc., 2015, 137, 5899; (o) C. M. Filloux and T. Rovis, J. Am. Chem. Soc., 2015, 137, 508; ( p) M. Hatano, Y. Ebe, T. Nishimura and H. Yorimitsu, J. Am. Chem. Soc., 2016, 138, 4010; (q) N. Kimura, T. Kochi and F. Kakiuchi, J. Am. Chem. Soc., 2017, 139, 14849; (r) J. Loup, D. Zell, J. C. A. Oliveira, H. Keil, D. Stalke and L. Ackermann, Angew. Chem., Int. Ed., 2017, 56, 14197.

4 (a) K. M. Gligorich, S. A. Cummings and M. S. Sigman, J. Am. Chem. Soc., 2007, 129, 14193; (b) Y. Iwai, K. M. Gligorich and M. S. Sigman, Angew. Chem., Int. Ed., 2008, 47, 3219; (c) L. Liao and M. S. Sigman, J. Am. Chem. Soc., 2010, 132, 10209. 5 (a) K. Semba, K. Ariyama, H. Zheng, R. Kameyama, S. Sakaki and Y. Nakao, Angew. Chem., Int. Ed., 2016, 55, 6275; (b) S. D. Friis, M. T. Pirnot and S. L. Buchwald, J. Am. Chem. Soc., 2016, 138, 8372; (c) S. D. Friis, M. T. Pirnot, L. N. Dupuis and S. L. Buchwald, Angew. Chem., Int. Ed., 2017, 56, 7242; (d) X. Lu, B. Xiao, Z. Zhang, T. Gong, W. Su, J. Yi, Y. Fu and L. Liu, Nat. Commun., 2016, 7, 11129; (e) S. A. Green, J. L. M. Matos, A. Yagi and R. A. Shenvi, J. Am. Chem. Soc., 2016, 138, 12779; (f) Y. He, Y. Cai and S. Zhu, J. Am. Chem. Soc., 2017, 139, 1061; $(g)$ F. Chen, K. Chen, Y. Zhang, Y. He, Y.-M. Wang and S. Zhu, J. Am. Chem. Soc., 2017, 139, 13929; (h) W. Li, J. K. Boon and Y. Zhao, Chem. Sci., 2018, 9, 600. 
6 L.-J. Xiao, L. Cheng, W.-M. Feng, M.-L. Li, J.-H. Xie and Q.-L. Zhou, Angew. Chem. Int. Ed., 2018, 57, 461.

7 For some recent examples on directed unactivated alkenes functionalization without metal hydride species, see: $(a)$ E. P. A. Talbot, T. A. Fernandes, J. M. McKenna and F. D. Toste, J. Am. Chem. Soc., 2014, 136, 4101; (b) A. Archambeau and T. Rovis, Angew. Chem., Int. Ed., 2015, 54, 13337; (c) Z. Liu, T. Zeng, K. S. Yang and K. M. Engle, J. Am. Chem. Soc., 2016, 138, 15122; (d) K. S. Yang, J. A. Gurak Jr, Z. Liu and K. M. Engle, J. Am. Chem. Soc., 2016, 138, 14705; (e) J. A. Gurak Jr, K. S. Yang, Z. Liu and K. M. Engle, J. Am. Chem. Soc., 2016, 138, 5805; (f) J. Derosa, V. T. Tran, M. N. Boulous, J. S. Chen and K. M. Engle, J. Am. Chem. Soc., 2017, 139, 10657; (g) Z. Liu, Y. Wang, Z. Wang, T. Zeng, P. Liu and K. M. Engle, J. Am. Chem. Soc., 2017, 139, 11261; (h) J. A. Gurak Jr and K. M. Engle, Synlett, 2017, 28, 2057; (i) B. Shrestha, P. Basnet, R. K. Dhungana, S. Kc, S. Thapa, J. M. Sears and R. Giri, J. Am. Chem. Soc., 2017, 139, 10653; (j) S. Guin, A. Deb, P. Dolui, S. Chakraborty, V. K. Singh and D. Maiti, ACS Catal., 2018, 8, 2664; (k) A. Deb, A. Hazra, Q. Peng, R. S. Paton and D. Maiti, J. Am. Chem. Soc., 2017, 139, 763; (l) A. Deb, S. Bag, R. Kancherla and D. Maiti, J. Am. Chem. Soc., 2014, 136, 13602.

8 For some directed hydrofunctionalizations involving $\mathrm{M}-\mathrm{H}$ species, see: hydrogenation: (a) R. H. Crabtree and M. W. Davis, J. Org. Chem., 1986, 51, 2655; (b) S. Song, S.-F. Zhu, Y.-B. Yu and Q.-L. Zhou, Angew. Chem., Int. Ed., 2013, 52, 1556; hydrosilyation: (c) J. B. Perales and D. L. Van Vranken, J. Org. Chem., 2001, 66, 7270; (d) Y. Kawasaki, Y. Ishikawa, K. Igawa and K. Tomooka, J. Am. Chem. Soc., 2011, 133, 20712; hydroboration: (e) D. A. Evans and G. C. Fu, J. Am. Chem. Soc., 1991, 113, 4042; (f) C. E. Garrett and G. C. Fu, J. Org. Chem., 1998, 63, 1370; $(g)$ M. Rubina, M. Rubin and V. Gevorgyan, J. Am. Chem. Soc., 2003, 125, 7198; (h) S. M. Smith and J. M. Takacs, J. Am. Chem. Soc., 2010, 132, 1740; (i) C. Sun, B. Potter and J. P. Morken, J. Am. Chem. Soc., 2014, 136, 6534; (j) Z.-D. Yang, R. Pal, G. L. Hoang, X. C. Zeng and
J. M. Takacs, ACS Catal., 2014, 4, 763; (k) G. L. Hoang, Z.-D. Yang, S. M. Smith, R. Pal, J. L. Miska, D. E. Pérez, L. S. W. Pelter, X. C. Zeng and J. M. Takacs, Org. Lett., 2015, 17, 940; (l) V. M. Shoba, N. C. Thacker, A. J. Bochat and J. M. Takacs, Angew. Chem., Int. Ed., 2016, 55, 1465; (m) S. Chakrabarty and J. M. Takacs, J. Am. Chem. Soc., 2017, 139, 6066; hydroacylation; (n) M. M. Coulter, P. K. Dornan and V. M. Dong, J. Am. Chem. Soc., 2009, 131, 6932; (o) M. M. Coulter, K. G. M. Kou, B. Galligan and V. M. Dong, J. Am. Chem. Soc., 2010, 132, 16330; (p) S. K. Murphy, A. Bruch and V. M. Dong, Angew. Chem., Int. Ed., 2014, 53, 2455; (q) S. K. Murphy, A. Brucha and V. M. Dong, Chem. Sci., 2015, 6, 174; hydroformylation; $(r)$ C. L. Joe, T. P. Blaisdell, A. F. Geoghan and K. L. Tan, J. Am. Chem. Soc., 2014, 136, 8556; (s) I. J. Krauss, C. C.-Y. Wang and J. L. Leighton, J. Am. Chem. Soc., 2001, 123, 11514; $(t)$ A. D. Worthy, L. Joe, T. E. Lightburn and K. L. Tan, J. Am. Chem. Soc., 2010, 132, 14757; (u) B. Breit and D. Breuninger, J. Am. Chem. Soc., 2004, 126, 10244.

9 (a) A. F. Döbber, R. H. Phoa, B. W. Abbassi, B. W. Stringer, T. G. Day, M. Johns, C. P. Abadleh and L. Munoz, ACS Med. Chem. Lett., 2017, 8, 395; (b) P. Prusevich, J. H. Kalin, S. A. Ming, M. Basso, J. Givens, X. Li, J. Hu, M. S. Taylor, A. M. Cieniewicz, P.-Y. Hsiao, R. Huang, H. Roberson, N. Adejola, L. B. Avery, R. A. Casero Jr, S. D. Taverna, J. Qian, A. J. Tackett, R. R. Ratan, O. G. McDonald, A. P. Feinberg and P. A. Cole, ACS Chem. Biol., 2014, 9, 1284; (c) Y.-Z. Xu, X.-Y. Gu, S.-J. Peng, J.-G. Fang, Y.-M. Zhang, D.-J. Huang, J.-J. Chen and K. Gao, Eur. J. Med. Chem., 2015, 94, 284.

10 CCDC 1838875 (3b) contains the supplementary crystallographic data. $\dagger$

11 (a) G. Huang and P. Liu, ACS Catal., 2016, 6, 809; (b) M. Liu, P. Yang, M. K. Karunananda, Y. Wang, P. Liu and K. M. Engle, J. Am. Chem. Soc., 2018, 140, 5805; (c) Z. Liu, H.-Q. Ni, T. Zeng and K. M. Engle, J. Am. Chem. Soc., 2018, 140, 3223. 